\title{
Diffuse large B cell lymphoma involving Meckel's cave masquerading as biopsy- negative giant cell arteritis: a case report
}

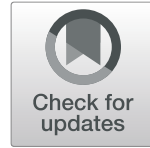

\author{
Matthew J. Samec ${ }^{1 *}$, Andres G. Madrigal ${ }^{2}$, Charlotte H. Rydberg ${ }^{3}$ and Matthew J. Koster ${ }^{4}$
}

\begin{abstract}
Background: Given the absence of consensus diagnostic criteria for giant cell arteritis, clinicians may encounter difficulty with identification of new-onset headache in patients older than age 50 years presenting with visual changes and elevated inflammatory markers, particularly if temporal artery biopsies are performed and negative.

Case presentation: We present a case of a 57-year-old white man with headache, diplopia, and jaw paresthesia initially diagnosed and managed as steroid-refractory biopsy-negative giant cell arteritis. Further investigation disclosed evidence of soft tissue infiltration into Meckel's (trigeminal) cave bilaterally. Positron emission tomography suggested the presence of a lymphoproliferative disorder. Histology confirmed the diagnosis of diffuse large B cell lymphoma.

Conclusions: Metastatic involvement in Meckel's cave in diffuse large B cell lymphoma is extremely rare and presents a diagnostic challenge. Patients with suspicion of giant cell arteritis should undergo advanced imaging, particularly those with negative biopsy, atypical features, or lack of response to standard therapy, in order to assess for the presence of large-vessel vasculitis or other mimicking pathologies.
\end{abstract}

Keywords: Lymphoma, Metastatic, Trigeminal nerve, Giant cell arteritis

\section{Background}

The diagnosis of giant cell arteritis (GCA) is based on clinical assessment of signs, symptoms, and laboratory features suggestive of the disease. Although non-invasive arterial imaging has shown increasing promise, the gold standard for diagnosis is confirmation through positive temporal artery biopsy (TAB) $[1,2]$. Due to the lack of validated and approved diagnostic criteria for GCA, clinicians may inaccurately use criteria intended for research classification to diagnose this condition [3]. Here we describe a case of elevated inflammatory markers, frontal headache, and visions changes that was initially

\footnotetext{
* Correspondence: samec.matthew@mayo.edu

'Department of Internal Medicine, Mayo Clinic College of Medicine and Science, Rochester, MN 55905, USA

Full list of author information is available at the end of the article
}

diagnosed as biopsy-negative GCA for which additional evaluation revealed a rare mimicking condition.

\section{Case description}

A 57-year-old white man presented with a 3-month history of new-onset, severe, bi-frontal headaches and a $13.6 \mathrm{~kg}(30-\mathrm{lb})$ weight loss. Local emergency room evaluation revealed a negative computed tomography (CT) scan of his head. Laboratory findings included an elevated erythrocyte sedimentation rate (ESR) of $80 \mathrm{~mm} /$ hour and C-reactive protein (CRP) of $55.3 \mathrm{mg} / \mathrm{L}$. He was discharged with pain control.

During follow-up with his local primary provider, his headache persisted and bilateral jaw pain and left facial numbness had developed. He was started on prednisone $60 \mathrm{mg} /$ day for presumed GCA with partial improvement in his headache. Bilateral temporal artery biopsies were

C C The Author(s). 2020 Open Access This article is licensed under a Creative Commons Attribution 4.0 International License, which permits use, sharing, adaptation, distribution and reproduction in any medium or format, as long as you give appropriate credit to the original author(s) and the source, provide a link to the Creative Commons licence, and indicate if changes were made. The images or other third party material in this article are included in the article's Creative Commons licence, unless indicated otherwise in a credit line to the material. If material is not included in the article's Creative Commons licence and your intended use is not permitted by statutory regulation or exceeds the permitted use, you will need to obtain permission directly from the copyright holder. To view a copy of this licence, visit http://creativecommons.org/licenses/by/4.0/ The Creative Commons Public Domain Dedication waiver (http://creativecommons.org/publicdomain/zero/1.0/) applies to the data made available in this article, unless otherwise stated in a credit line to the data. 
performed 3 days later and were negative. Prednisone was subsequently discontinued. Two weeks later his headache progressed and right eye horizontal diplopia and perioral numbness developed. Magnetic resonance imaging (MRI) of his brain was performed and interpreted as normal. He was admitted for pulse-dose steroids (1000 mg daily for 3 days) which led to resolution of visual symptoms and was discharged on prednisone $60 \mathrm{mg} /$ day. Tapering below $50 \mathrm{mg} /$ day was unsuccessful due to rising inflammatory markers, symptom progression, and return of diplopia. Severe left hip pain developed for which plain radiographs were obtained but negative for fracture or avascular necrosis.

On referral to our institution he continued to have ongoing headache and left jaw numbness despite 6 weeks of high-dose glucocorticoids $(80 \mathrm{mg} /$ day). Left hip pain had worsened to the point of wheelchair dependency. His past medical history was remarkable for atrial fibrillation for which he was receiving warfarin $2 \mathrm{mg} /$ day and diltiazem $240 \mathrm{mg} /$ day. Social history was notable for lack of tobacco or alcohol use and absence of known environmental exposures during his employment as an office manager. Aside from prostate cancer in his father, our patient's family history was negative for other pertinent diagnoses of additional malignancies or autoimmune conditions. Laboratory evaluation noted an ESR $72 \mathrm{~mm} /$ hour, CRP $53 \mathrm{mg} / \mathrm{L}$, hemoglobin $11.1 \mathrm{~g} / \mathrm{dL}$, leukocytes $5.2 \times 10^{9} / \mathrm{L}$ and platelets $110 \times 10^{9} / \mathrm{L}$, international normalized ratio (INR) 2.3 , creatinine $1.04 \mathrm{mg} / \mathrm{dL}$, calcium $11.6 \mathrm{mg} / \mathrm{dL}$, alanine aminotransferase $106 \mathrm{U} / \mathrm{L}$, aspartate aminotransferase $64 \mathrm{U} / \mathrm{L}$, alkaline phosphatase $360 \mathrm{U} / \mathrm{L}$, total bilirubin $1.2 \mathrm{mg} / \mathrm{dL}$, total protein $5.1 \mathrm{~g} / \mathrm{dL}$, and albumin $3.4 \mathrm{~g} / \mathrm{dL}$. Previously obtained autoimmune serologies were negative for antinuclear and extractable nuclear antigens as well as rheumatoid factor, anti-cyclic citrullinated peptide, myeloperoxidase, and proteinase- 3 antibodies.

His vital signs demonstrated a heart rate of 95 beats per minute, blood pressure of $94 / 44 \mathrm{~mm} \mathrm{Hg}$, respiratory rate of 12 per minute, oxygenation saturation of $96 \%$, and weight of $144 \mathrm{~kg}$ with body mass index (BMI) of $48.6 \mathrm{~kg} / \mathrm{m}^{2}$. An examination was notable for a Cushingoid appearance and morbid obesity. Evaluation of adenopathy and splenomegaly was limited due to body habitus. Pertinent cardiovascular findings included irregularly irregular pulse without murmurs. Upper and lower arterial pulses were normal and symmetric. Common superficial temporal artery palpation was without tenderness or nodularity. Trace pitting edema was noted to the ankle bilaterally. Breath sounds were equal and symmetric without wheezing or rhonchi. Aside from scattered bruising at site of venipuncture, no cutaneous abnormalities were noted. A neurologic examination showed normal speech without language deficits. Visual acuity was $20 / 20$ bilaterally. Cranial nerves $2-12$ were assessed and normal except for mild esotropia of his right eye and hypoesthesia to light touch and pinprick over the left mandibular region of the left trigeminal nerve. The remaining dermatomes evaluated showed normal sensation. Reflexes were normal and symmetric throughout and toes were down-going bilaterally. No ataxia was observed. A musculoskeletal examination demonstrated normal range of motion of upper extremities without deficit. Marked pain was noted on passive and active range of motion of his left hip.

Given the persistent headache despite high-dose glucocorticoids and atypical features, alternative etiologies were suspected. The local MRI of his brain was reviewed and evidence of abnormal enhancing soft tissue involving Meckel's cave bilaterally with extension through the foramen ovale was noted (Fig. 1a). The differential diagnosis for infiltrative process in Meckel's cave included sarcoidosis as well as primary or secondary neoplastic lesions such as meningioma, nasopharyngeal carcinoma, schwannoma, neurofibroma, and lymphoma $[4,5]$. The presence of constitutional symptoms and elevated inflammatory markers suggested a secondary process with associated intracranial involvement. As such, positron emission tomography (PET)-CT was obtained. This demonstrated extensive hypermetabolic lesions throughout the axial and appendicular skeleton, including the skull base, as well as fluorodeoxyglucose (FDG)-avid lymph nodes above and below the diaphragm (Fig. 1c). MRI of his left hip revealed diffusely abnormal marrow signal suggestive of infiltrative disease. A cervical lymph node biopsy demonstrated evidence of diffuse large B cell lymphoma and staging bone marrow biopsy revealed a hypercellular marrow (90\%) with diffuse large B cell lymphoma involving $70 \%$ of the total cellularity (Fig. 2). Initiation of high-dose methotrexate $\left(3.5 \mathrm{~g} / \mathrm{m}^{2}\right)$, rituximab $\left(375 \mathrm{mg} / \mathrm{m}^{2}\right)$, cyclophosphamide $\left(750 \mathrm{mg} / \mathrm{m}^{2}\right)$, hydroxydaunorubicin $\left(50 \mathrm{mg} / \mathrm{m}^{2}\right)$, Oncovin (vincristine; $2 \mathrm{mg}$ ), and prednisone (255 mg) (MR-CHOP; 21-day cycle) resulted in interval improvement in his headache and visual symptoms (Fig. 1b, d).

Ten months after initial diagnosis and 4 months after completion of his sixth cycle of MR-CHOP, our patient re-presented with bilateral lower extremity weakness and PET-CT showed recurrence of disease with evidence of neurolymphomatosis of multiple cervical, thoracic, and sacral nerve roots. Intrathecal cytarabine $(50 \mathrm{mg})$ was given and ibrutinib $(140 \mathrm{mg} /$ day $)$ was initiated, resulting in initial findings of improved strength and subsequent decreased nerve root FDG-avidity.

\section{Discussion}

This case highlights a notably rare manifestation of metastatic lymphoma presenting with involvement of 


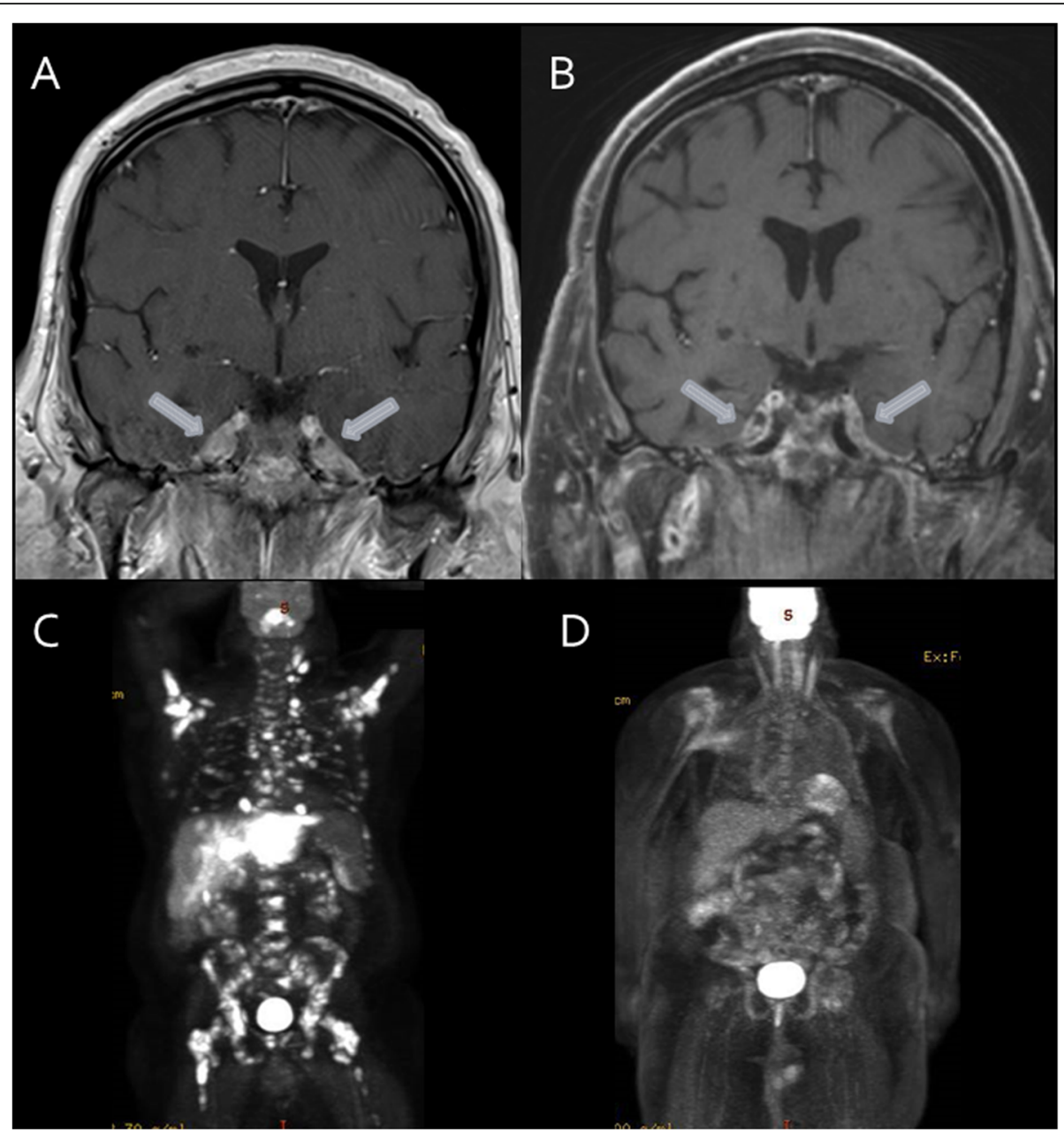

Fig. 1 Diffuse large B cell lymphoma involvement on magnetic resonance imaging and positron emission tomography-computed tomography. Magnetic resonance images of brain show: a abnormal enhancement of Meckel's cave bilaterally with extension through the foramen ovale (arrows) before chemotherapy and $\mathbf{b}$ decreased soft tissue in Meckel's cave bilaterally (arrows) after chemotherapy. Positron emission tomography-computed tomography scans show: c extensive hypermetabolic lesions throughout the axial and appendicular skeleton, including the skull base, as well as fluorodeoxyglucose-avid lymph nodes above and below the diaphragm before chemotherapy and $\mathbf{d}$ marked response of all hypermetabolic lesions after chemotherapy

Meckel's cave, which was initially mischaracterized as biopsy-negative GCA. Awareness of the neurologic features associated with skull base tumors involving Meckel's cave as well as identification of atypical features of elderly-onset headache that should raise suspicion for etiologies other than GCA are needed to educate providers in order to appropriately identify, diagnose, and manage these uncommon presentations that are associated with high morbidity.

Meckel's cave, also known as cavum trigeminale, is a cerebrospinal fluid (CSF)-containing dural pouch in the middle cranial fossa connecting the cavernous sinus to the prepontine cistern of the posterior fossa [5]. This structure contains the Gasserian ganglion of the trigeminal nerve as well as the three postganglionic trigeminal roots: ophthalmic (V1), maxillary (V2), and mandibular
(V3) [5]. Tumors in Meckel's cave are uncommon but the most frequent neoplasms at this site include trigeminal nerve sheath tumors, schwannomas, meningiomas, neurofibromas, nasopharyngeal carcinoma, and leptomeningeal metastases from solid organ malignancy (renal cell, lung, and breast) [4-7]. Metastatic lymphoma involving Meckel's cave is rare with as few as 11 previously reported cases [8]. The most notable features of Meckel's cave involvement include trigeminal neuralgia, facial numbness, and diplopia [6,9]; the latter typically due to sixth nerve palsy resulting from the close proximity of the V1 branch in the cavernous sinus.

MRI is the imaging modality of choice for evaluation of patients with trigeminal neuralgia in which concern of Meckel's cave involvement is suspected and should be performed with T1-weighted and T2-weighted imaging, 


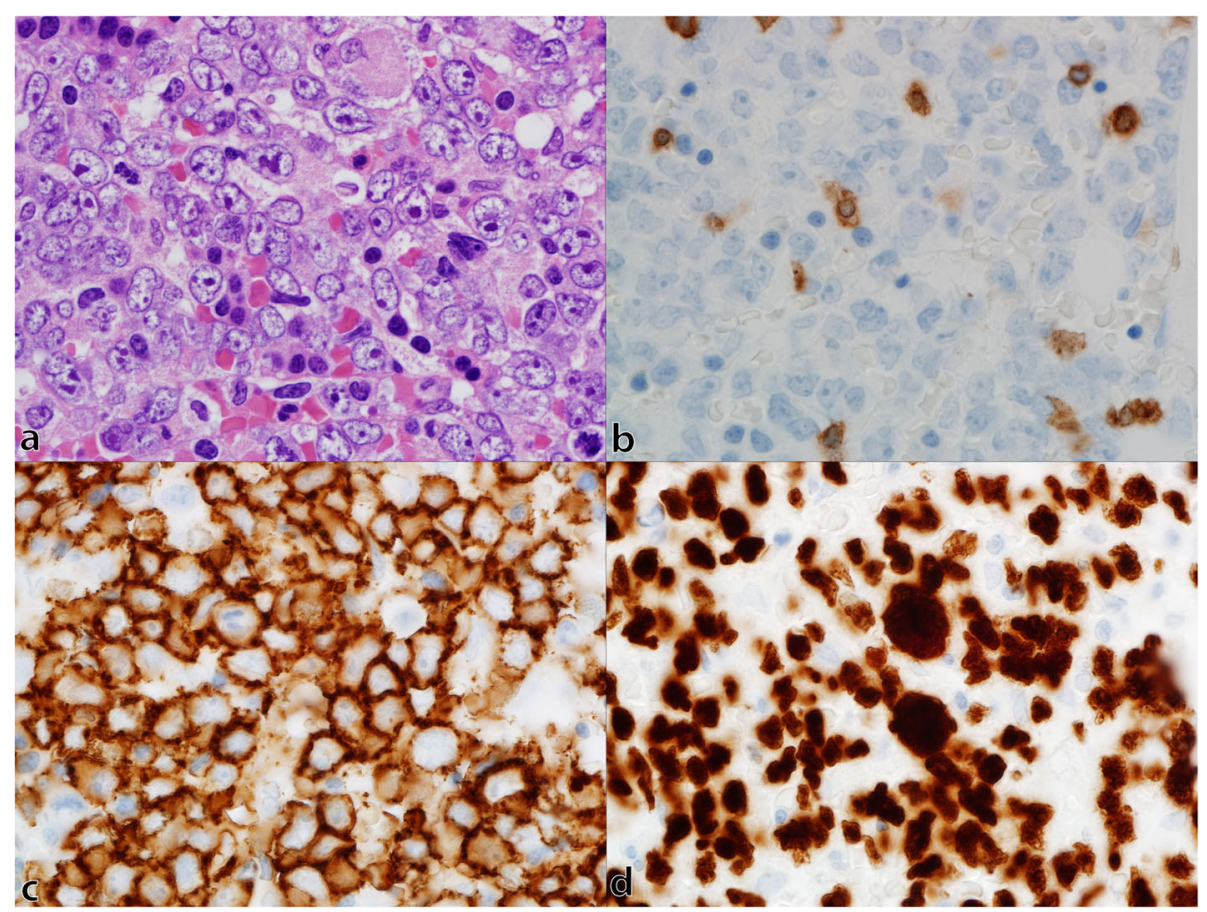

Fig. 2 Bone marrow involvement by diffuse large B cell lymphoma. Photomicrographs of bone marrow trephine biopsy show: a medium to large neoplastic lymphocytes with nuclear irregularity, dispersed chromatin and variably sized nucleoli and background hematopoietic precursors on hematoxylin and eosin stain, $\mathbf{b}$ rare scattered T cells highlighted by CD3 immunohistochemistry, $\mathbf{c}$ membranous staining of neoplastic B cells by CD20 immunohistochemistry, and $\mathbf{d}$ nuclear staining of neoplastic B cells by PAX5 immunohistochemistry. a-d; $\times 1000$

short-tau inversion recovery, and gadolinium-enhanced T1-images with fat suppression [5]. Radiographic features suggestive of pathology of Meckel's cave include nerve enlargement, enhancement, or trigeminal cistern CSF effacement [5]. Unfortunately if these findings are subtle, particularly if they are symmetrical, they can be overlooked, as occurred initially in the presented case.

Due to its rarity, limited information is present in regards to the best treatment for patients with metastatic lymphoma involving Meckel's cave. Treatment with highdose methotrexate and whole brain radiation has been used with variable outcomes [10]. Consolidation therapy with rituximab, cyclophosphamide, hydroxydaunorubicin, Oncovin (vincristine), and prednisone (R-CHOP) has shown benefit in case reports [11] and led to improvement of headache and visual symptoms in our patient when combined with high-dose methotrexate. Relapsing/refractory patients, as observed in our case, may require additional therapies such as single agent ibrutinib, rituximab plus ifosfamide-carboplatin-etoposide (RICE), or chimeric antigen receptor $\mathrm{T}$ cell (CAR-T) therapy [12].

In addition to its rarity, the described case provides a cautionary tale in evaluating patients with headache and inflammatory marker elevation. While classification criteria for GCA include an age at disease onset of $\geq 50$ years, new-onset headache, temporal artery abnormality including tenderness to palpation or decreased pulsation,
ESR $\geq 50 \mathrm{~mm} /$ hour, and an abnormal TAB with characteristic features [13], the intended use of these criteria is to create homogenous cohorts of patients for research purposes by distinguishing individuals with GCA from other cases with known vasculitis. Currently there are no approved or endorsed diagnostic criteria for GCA. Consequently, classification criteria for GCA are often incorrectly used in routine clinical practice for assistance in diagnosis. Although the described patient met criteria for age, headache, and inflammatory markers, his additional atypical features, including negative temporal artery biopsies, lack of response to high-dose steroids, and presence of trigeminal neuralgia, should raise suspicion for alternative etiologies.

Positive TAB has historically been considered the gold standard for diagnosis of GCA. However, given temporal artery involvement is not uniformly contiguous (that is, skip lesions) it is possible for patients to have classical features of GCA but have a negative biopsy (so-called biopsy-negative GCA). Clinicians should be cautious to exclude other mimicking conditions in this circumstance, particularly if features are atypical. It is noteworthy that among patients with initial suspicion of GCA undergoing TAB, 80\% may have an alternative diagnosis [14]. Among a study of 123 patients with a negative TAB who were not diagnosed with GCA, common alternative diagnoses included self-limited disease 
(23\%), isolated polymyalgia rheumatica (18\%), stroke or transient ischemic attack (17\%), and, less commonly, infection (5\%) or malignancy (2\%) [14]. Furthermore, not all abnormal temporal artery biopsies are due to GCA. In fact, rare but important mimics to consider include perivascular and intravascular lymphoma which may present with vision loss, headache, and increased inflammatory markers; however, pathology shows a strong neoplastic lymphoid infiltrate [15-18].

Glucocorticoids have been the cornerstone of treatment in patients with GCA. With high-dose glucocorticoids, significant symptomatic improvement can occur within as few as 24-48 hours [19] but may require up to 2 weeks. As such, a presumed diagnosis of GCA should be questioned if a therapeutic trial of high-dose glucocorticoids fails to result in marked clinical improvement in that time frame [19].

The European League Against Rheumatism (EULAR) recommends early imaging in patients with suspected GCA in capable centers to supplement clinical criteria [20]. For patients with cranial symptoms, evaluation of the temporal arteries by ultrasound or biopsy is prudent, but, if negative, additional imaging should be considered to support a suspected diagnosis of GCA. The use of PET-CT or thoracic magnetic resonance angiography (MRA)/CT angiography (CTA) are particularly helpful to evaluate suspected extracranial large vessel vasculitis but are also useful in identifying potential mimics, as was the circumstance in our case. The authors propose a suggested diagnostic algorithm to assist clinicians in evaluating patients with suspected GCA (Fig. 3).

\section{Conclusion}

Our case illustrates an atypical presentation of diffuse large B cell lymphoma initially misdiagnosed as biopsynegative GCA. Lack of improvement of inflammatory markers and persistent symptoms despite high-dose glucocorticoids should prompt a thorough investigation of alternative diagnoses. Early imaging in patients with suspected GCA should occur to assist in confirming the diagnosis of GCA and ruling out alternative etiologies. Finally, pathology within Meckel's cave, though rare, can mimic symptoms of trigeminal neuralgia and lead to further diagnostic challenges in patients presenting with facial numbness.

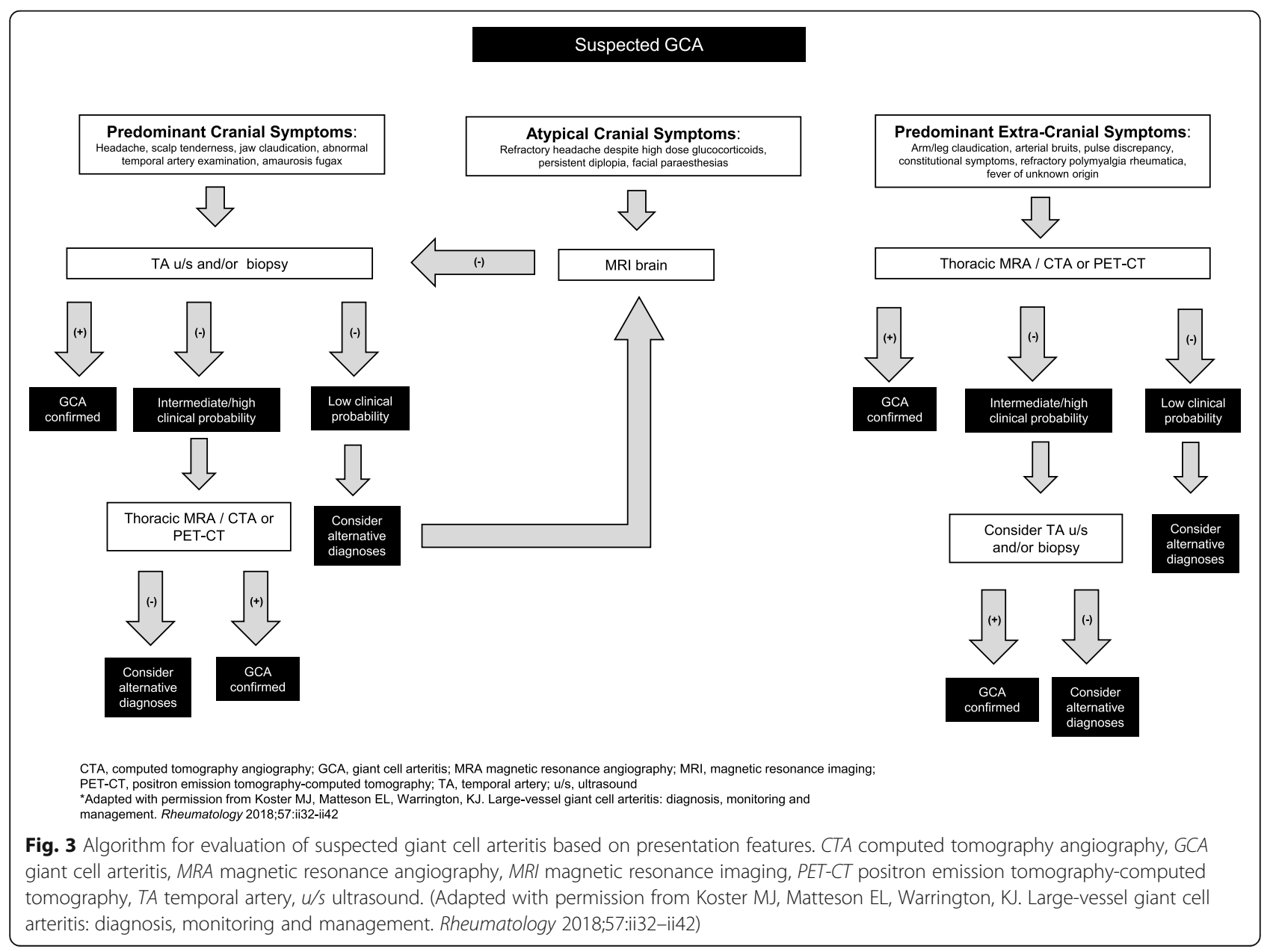




\section{Abbreviations}

BMl: Body mass index; CRP: C-reactive protein; CSF: Cerebrospinal fluid; $\mathrm{CT}$ : Computed tomography; CTA: Computed tomography angiography; ESR: Erythrocyte sedimentation rate; EULAR: European League Against Rheumatism; FDG: Fluorodeoxyglucose; GCA: Giant cell arteritis; INR: International normalized ratio; MRA: Magnetic resonance angiography; MR-CHOP: Methotrexate, rituximab, cyclophosphamide, hydroxydaunorubicin Oncovin (vincristine), and prednisone; MRI: Magnetic resonance imaging; PET: Positron emission tomography; R-CHOP: Rituximab, cyclophosphamide hydroxydaunorubicin, Oncovin (vincristine), and prednisone; TAB: Temporal artery biopsy

\section{Acknowledgements}

Not applicable.

\section{Authors' contributions}

MJS and MJK gathered patient data regarding clinical presentation. MJS and MJK drafted the initial manuscript. AGM performed the histological examination of the bone marrow, CHR reviewed and prepared radiologic data, and both were major contributors to the final manuscript. All authors read and approved the final manuscript.

\section{Funding}

None.

\section{Availability of data and materials}

Not applicable.

\section{Ethics approval and consent to participate}

Waived.

\section{Consent for publication}

Written informed consent was obtained from the patient for publication of this case report and any accompanying images. A copy of the written consent is available for review by the Editor-in-Chief of this journal.

\section{Competing interests}

The authors declare that they have no competing interests.

\section{Author details}

${ }^{1}$ Department of Internal Medicine, Mayo Clinic College of Medicine and Science, Rochester, MN 55905, USA. ${ }^{2}$ Department of Hematopathology, Mayo Clinic College of Medicine and Science, Rochester, MN 55905, USA. 3Department of Radiology, Mayo Clinic College of Medicine and Science, Rochester, MN 55905, USA. ${ }^{4}$ Division of Rheumatology, Mayo Clinic College of Medicine and Science, Rochester, MN 55905, USA.

\section{Received: 13 July 2019 Accepted: 23 March 2020}

Published online: 10 May 2020

\section{References}

1. Dasgupta B, Borg FA, Hassan N, Alexander L, Barraclough K, Bourke B, et al. $B S R$ and BHPR guidelines for the management of giant cell arteritis. Rheumatology (Oxford). 2010;49(8):1594-7.

2. Davies CG, May DJ. The role of temporal artery biopsies in giant cell arteritis. Ann R Coll Surg Engl. 2011;93(1):4-5.

3. Koster MJ, Matteson EL, Warrington KJ. Large-vessel giant cell arteritis: diagnosis, monitoring and management. Rheumatology (Oxford). 2018; 57(suppl_2):ii32-42.

4. Donia MM, Gamaleldin OA, Abdo AM, Desouky SE, Helmy SAS. Intracranial neoplastic lesions of the trigeminal nerve: How MRI can help. Egypt J Radiol Nucl Med. 2017;48(4):1035-41.

5. Malhotra A, Tu L, Kalra VB, Wu X, Mian A, Mangla R, et al. Neuroimaging of Meckel's cave in normal and disease conditions. Insights Imaging. 2018;9(4): 499-510.

6. Beck DW, Menezes AH. Lesions in Meckel's cave: variable presentation and pathology. J Neurosurg. 1987;67(5):684-9.

7. Soni CR, Kumar G, Sahota P, Miller DC, Litofsky NS. Metastases to Meckel's cave: report of two cases and comparative analysis of malignant tumors with meningioma and schwannoma of Meckel's cave. Clin Neurol Neurosurg. 2010;112(10):927-32.
8. Zhao H, Tang DZ, Zhu J, Zhang X, Tang YD, Li ST. Diffuse Large B Cell Lymphoma Presented as Trigeminal Neuralgia: 2 Cases Reported and Literature Review. World Neurosurg. 2019;123:383-9.

9. Yuh WT, Wright DC, Barloon TJ, Schultz DH, Sato Y, Cervantes CA. MR imaging of primary tumors of trigeminal nerve and Meckel's cave. AJR Am J Roentgenol. 1988;151(3):577-82.

10. Kinoshita M, Izumoto S, Oshino S, Nonaka M, Moriuchi S, Maruno M, et al. Primary malignant lymphoma of the trigeminal region treated with rapid infusion of high-dose MTX and radiation: case report and review of the literature. Surg Neurol. 2003;60(4):343-8. discussion 8.

11. Ang JW, Khanna A, Walcott BP, Kahle KT, Eskandar EN. Central nervous system lymphoma presenting as trigeminal neuralgia: A diagnostic challenge. J Clin Neurosci. 2015;22(7):1188-90.

12. Liu Y, Barta SK. Diffuse large B-cell lymphoma: 2019 update on diagnosis, risk stratification, and treatment. Am J Hematol. 2019:94(5):604-16.

13. Hunder GG, Bloch DA, Michel BA, Stevens MB, Arend WP, Calabrese LH, et al. The American College of Rheumatology 1990 criteria for the classification of giant cell arteritis. Arthritis Rheum. 1990;33(8):1122-8.

14. Bornstein G, Barshack I, Koren-Morag N, Ben-Zvi I, Furie N, Grossman C. Negative temporal artery biopsy: predictive factors for giant cell arteritis diagnosis and alternate diagnoses of patients without arteritis. Clin Rheumatol. 2018:37(10):2819-24.

15. Dinkin M, Lavi E, Winterkorn J, Oliveira C, Merkler AE. Ischemic Optic Neuropathy Secondary to Intravascular Lymphoma. J Neuroophthalmol. 2019;39(3):313-8.

16. Emmanuela Obiorah I, Ozdemirli M. Intravascular Large B-Cell Lymphoma Mimicking Temporal Arteritis. Case Rep Rheumatol. 2018;2018:5364985.

17. Linxweiler M, Hasenfus A, Wolf G, Schick B. Perivascular marginal zone lymphoma mimicking temporal arteritis. Otolaryngol Head Neck Surg. 2015; 152(1):187-8.

18. Masood I, While B, Mudhar HS. Perivascular mantle cell lymphoma affecting a temporal artery--a highly unusual cause of temporal headache. Cardiovasc Pathol. 2011:20(4):244-6.

19. Chatterjee S, Flamm SD, Tan CD, Rodriguez ER. Clinical diagnosis and management of large vessel vasculitis: giant cell arteritis. Curr Cardiol Rep. 2014;16(7):498

20. Dejaco C, Ramiro S, Duftner C, Besson FL, Bley TA, Blockmans D, et al. EULAR recommendations for the use of imaging in large vessel vasculitis in clinical practice. Ann Rheum Dis. 2018;77(5):636-43.

\section{Publisher's Note}

Springer Nature remains neutral with regard to jurisdictional claims in published maps and institutional affiliations.

Ready to submit your research? Choose BMC and benefit from:

- fast, convenient online submission

- thorough peer review by experienced researchers in your field

- rapid publication on acceptance

- support for research data, including large and complex data types

- gold Open Access which fosters wider collaboration and increased citations

- maximum visibility for your research: over $100 \mathrm{M}$ website views per year

At BMC, research is always in progress.

Learn more biomedcentral.com/submissions 